\title{
Do saber ao ser: reflexões sobre a formação do médico de família e comunidade em serviço territorial de base comunitária
}

\author{
From knowing to being: reflections on the training of family and community physician in territorial \\ community based service
}

\section{Del saber al ser: reflexiones sobre la formación del médico de familia y comunidad en servicio territorial de base comunitaria}

\author{
André Cordeiro Marques ${ }^{1}[0$ \\ ${ }^{1}$ Secretaria Municipal de Saúde do Ceará. Fortaleza, CE, Brasil.
}

\section{Resumo}

Objetivos: O presente estudo buscou a partir das reflexões sobre o processo de execução e manutenção de um grupo para a promoção de saúde em uma unidade de atenção primária em saúde no município de Fortaleza, CE, sistematizar a experiência de organização, execução e manutenção de um grupo para a promoção da saúde em uma unidade de atenção primária em saúde no município de Fortaleza, CE correlacionando a experiência do processo grupal com os referenciais teóricos da Atenção Primária em Saúde (APS) e da Abordagem Sistêmica Comunitária (ASC), apontar desafios e potencialidades dessa abordagem no contexto da APS e seu potencial impacto sobre a saúde das comunidades e sobre a formação de especialistas em Medicina de Família e Comunidade. Métodos: Utilizou-se uma metodologia de sistematização de experiências em diálogo com as narrativas autobiográficas e o círculo de cultura. Resultados: A recuperação do processo vivido evidenciou o potencial da integração entre ferramentas da ASC, da Educação Popular e do Processo Grupal, ancorados no conhecimento e na aplicação dos princípios norteadores da Medicina de Família e Comunidade para a produção de mudanças no processo de trabalho do profissional médico e no seu contexto de atuação. Conclusão: Ao sistematizar o processo vivido e confrontá-lo com a teoria da implicação do sujeito vieram à tona aspectos do fazer médico na APS que de outra forma permaneceriam restritos e implícitos no modo de Ser Médico de Família e Comunidade. A narrativa propõe questionamentos quanto ao impacto do desse fazer médico sobre a saúde das populações, individual e coletivamente e sobre o próprio profissional enquanto ser humano passível de adoecimento e dotado de infinitas potencialidades. Caminhos possíveis e as possibilidades de mudança e superação do modelo médico-assistencialista hegemônico e vigente foram propostos a partir desta narrativa plena de signos e significados.

Palavras-chave: Medicina de Família e Comunidade; Educação Médica; Promoção da Saúde; Educação em Saúde; Atenção Primária à Saúde

Como citar: Marques AC. Do saber ao ser: reflexões sobre a formação do médico de família e comunidade em serviço territorial de base comunitária. Rev Bras Med Fam Comunidade. 2019;14(41):1897. https://doi.org/10.5712/rbmfc14(41)1897

\section{Autor correspondente: André Cordeiro Marques. E-mail: acmmfc@gmail.com Fonte de financiamento: declara não haver. \\ Parecer CEP: não se aplica.}

Procedência e revisão por pares: revisado por pares. Recebido em: 09/10/2018. Aprovado em: 03/09/2019. 


\begin{abstract}
Objectives: The present study sought from the reflections on the process of execution and maintenance of a group for health promotion in a primary health care unit in the city of Fortaleza, CE, to systematize the experience of organization, execution and maintenance of a group for the promotion of health in a primary health care unit in the city of Fortaleza, $C E$, correlating the experience of the group process with the theoretical frameworks of Primary Health Care (PHC) and the Community Systemic Approach (CSA), pointing out challenges and potentialities of this approach in the context of PHC and its potential impact on the health of communities and on the training of specialists in Family and Community Medicine. Methods: A methodology of experience systematization was used in dialogue with the autobiographical narratives and the circle of culture. Results: The recovery of the experienced process evidenced the potential of the integration between ASC, Popular Education and Group Process tools, anchored in the knowledge and application of the guiding principles of Family and Community Medicine for producing changes in the work process of the medical professional and in its context of action. Conclusion: By systematizing the experienced process and confronting it with the theory of subject implication, aspects of medical practice in APS that would otherwise remain restricted and implicit in the mode of Family and Community Medical Being emerged The narrative proposes questions about the impact of this medical practice on the health of populations, individually and collectively, and about the professional himself as a human being that can be endured and endowed with infinite potentialities. Possible paths and the possibilities of change and overcoming of the hegemonic and current medical model were proposed from this narrative full of signs and meanings.
\end{abstract}

Keywords: Family Practice; Education, Medical; Health Promotion; Health Education; Primary Health Care

\title{
Resumen
}

Objetivos: El presente estudio buscó a partir de las reflexiones sobre el proceso de ejecución y mantenimiento de un grupo para la promoción de salud en una unidad de atención primaria en salud en el municipio de Fortaleza, CE, sistematizar la experiencia de organización, ejecución y mantenimiento de un grupo para la promoción de la salud en una unidad de atención primaria en salud en el municipio de Fortaleza, CE, correlacionando la experiencia del proceso grupal con los referentes teóricos de la Atención Primaria en Salud (APS) y del Enfoque Sistémico Comunitario (ASC), señalar desafíos y potencialidades de este enfoque en el contexto de la APS y su potencial impacto sobre la salud de las comunidades y sobre la formación de especialistas en Medicina de Familia y Comunidad. Métodos: Se utilizó una metodología de sistematización de experiencias en diálogo con las narrativas autobiográficas y el círculo de cultura. Resultados: La recuperación del proceso vivido evidenció el potencial de la integración entre herramientas de la ASC, de la Educación Popular y del Proceso Grupal, anclados en el conocimiento y en la aplicación de los principios orientadores de la Medicina de Familia y Comunidad para la producción de cambios en el proceso de trabajo del profesional médico y en su contexto de actuación. Conclusión: Al sistematizar el proceso vivido y confrontarlo con la teoría de la implicación del sujeto surgieron aspectos del hacer médico en la APS que de otra forma permanecerían restringidos e implícitos en el modo de Ser Médico de Familia y Comunidad. La narrativa propone cuestionamientos en cuanto al impacto del de hacer médico sobre la salud de las poblaciones, individual y colectivamente y sobre el propio profesional como ser humano pasible de enfermedad y dotado de infinitas potencialidades. Se propusieron caminos posibles y las posibilidades de cambio y superación del modelo médico-asistencialista hegemónico y vigente a partir de esta narrativa llena de signos y significados.

Palabras clave: Medicina Familiar y Comunitaria; Educación Médica; Promoción de la Salud; Educación en Salud; Atención Primaria de Salud

\section{A atenção primária e o cuidado integral em saúde}

A atenção primária em saúde (APS), como porta de entrada preferencial para o Sistema Único de Saúde (SUS) e responsável pelo cuidado continuado e integral das pessoas em sua área de abrangência, constitui-se em um tipo altamente personalizado de prestação de cuidado. ${ }^{1}$

Um dos caminhos para se chegar a essa personalização do cuidado pode se dar por meio de certas competências encarnadas na figura do Médico de Família e Comunidade (MFC) cuja prática ancora-se na abordagem centrada na pessoa. Essa, por sua vez, aponta para a humanização e individualização do cuidado prestado a pessoas em processo de adoecimento e contribui para efetivar a APS na coordenação do cuidado. Dessa forma, espera-se romper com uma prática médica excessivamente biomédica, fragmentada e centrada na doença e assim minimizarmos seus possíveis efeitos iatrogênicos.

A integração de conhecimentos da biomedicina, da sociologia e psicologia médica permite ao MFC a implementação de estratégias de cuidado mais factíveis e mais efetivas para a população sob sua responsabilidade. O estabelecimento de uma relação médico-paciente de confiança, lealdade e 
responsabilidade vai permear o desenvolvimento e consolidação do vínculo como condição fundamental para o estabelecimento desse cuidar específico.

Minha experiência como Residente em MFC entre 2006 e 2008 constituiu-se no pilar sobre o qual pude desenvolver e aperfeiçoar minha identidade profissional. A compreensão dos princípios que regem a especialidade e sua aplicação no trabalho cotidiano em um serviço de saúde de base territorial foram os fundamentos norteadores deste estudo.

A partir da análise do processo de estruturação e desenvolvimento de um grupo para promoção de saúde em nível comunitário, buscou-se ressaltar o potencial transformador do fazer profissional do MFC ao exercer sua atividade de maneira consciente e embasada nos referenciais teóricos que fundamentam a especialidade.

Para a realização deste estudo, utilizei uma metodologia qualitativa com caráter descritivo, na modalidade de Relato de Experiência. O presente relato foi elaborado a partir da Sistematização de Experiências ${ }^{1}$ cujo percurso está organizado em cinco tempos: a) os pontos de partida; b) formulação das questões iniciais; c) recuperação do processo vivido; d) a reflexão de fundo; e) os pontos de chegada. ${ }^{1}$

Como forma de recuperação do vivido, escolhemos a narrativa autobiográfica, por se tratar de um processo no qual estava inteiramente implicado. ${ }^{2} \mathrm{~A}$ partir de um exercício de visualização criativa com base nos registros materiais e visuais das atividades e de palavras geradoras ancoradas no círculo de cultura Freiriano, ${ }^{3}$ elaborei a narrativa sobre a qual agora disserto.

\section{O caminho percorrido}

As questões iniciais surgiram a partir das minhas inquietações a respeito da inserção da promoção da saúde na prática cotidiana do Médico de Família e Comunidade (MFC). As reflexões de fundo sobre o processo vivido se constituíram com base em questões norteadoras e foram trazidas para dialogar com os autores que escolhemos para orientar a construção do trabalho. ${ }^{4}$ Como pontos de chegada, podemos elencar algumas considerações produzidas a partir deste estudo sobre o meu fazer cotidiano enquanto MFC.

Segundo a Organização Pan-americana de Saúde, os estudos de demanda em ambulatórios gerais demonstram, ainda, que a metade das consultas se deve a cerca de apenas 30 diferentes diagnósticos, e o manejo adequado dos 50 diagnósticos mais frequentes permite a resolução de mais da metade da demanda médica em ambulatórios de atenção primária. ${ }^{5}$

Nesse sentido e considerando a realidade objetiva com a qual me deparava como profissional médico alguns questionamentos foram surgindo, os quais posteriormente iriam orientar a problematização sobre a experiência vivida. Segundo o modelo biomédico hegemônico, ao MFC é delegado apenas o papel de prescritor na maioria das vezes para algumas dezenas de afecções, provocando um reducionismo do fazer médico. Esse cerceamento do potencial transformador social do médico na APS acaba por frustrar o profissional médico que atua na porta de entrada do sistema, contribuindo para a redução da longevidade desse profissional na APS. Essa abordagem reducionista vai de encontro com os princípios da integralidade e da coordenação dos cuidados na APS e então a pergunta: O médico generalista está capacitado para lidar com essas contradições no âmbito da APS? 
Em 2006 falava-se em Programa de Saúde da Família (PSF) pautado nos princípios da MFC, o qual surgia como alternativa aos Centros de Saúde pautados em um modelo misto no qual profissionais especialistas focais abordavam os problemas de saúde mais prevalentes nas três áreas básicas da medicina (ginecologia-obstetrícia, pediatria e clínica médica). Com o fortalecimento do PSF, principalmente com a implementação de cursos de residência e especialização voltados para a atuação na APS, esse passou a constituir a Estratégia Saúde da Família (ESF).

Nesse percurso estavam em jogo duas concepções de cuidado: Uma higienista, biomédica, fragmentada, centrada na doença, prescritiva e hierárquica e outra humanística, integral, educativa, transformadora, centrada na pessoa, transversal e colaborativa.

"O tensionamento do modelo técnico assistencial vigente nos impele na busca de um referencial teórico que elabore de forma mais ampla o conjunto de elementos da estrutura social, e que tome o campo específico da relação entre a sociedade, o Estado e as políticas sociais como sua questão central". ${ }^{6}$

No conceito de território existencial, situacional e portador de muitos sentidos, o próprio usuário é o responsável pela construção de sua rede de cuidado. Assim, a construção e o fortalecimento dos vínculos existenciais e terapêuticos constituem-se como ferramentas fundamentais da medicina de família e comunidade aplicada nesses contextos.

Nesse momento tive um salto de compreensão sobre o papel do MFC enquanto ordenador principal do cuidado no modelo assistencial vigente como também dentro do território existencial do cuidado em saúde da população ao qual ele se vincula. Assim, o MFC se torna importante ponto de cuidado dentro da rede de atenção à saúde formal.

Na minha prática isso se deu com a saída dos especialistas do serviço, recaindo sobre mim a responsabilidade pelo suporte médico e pela retaguarda da unidade que contava com três equipes de Saúde da Família (ESF), porém somente eu como médico de referência no serviço. O aumento da demanda por consultas individuais, a apreensão da gestão local e insatisfação da população assistida em relação aos processos de trabalho denunciavam barreiras de acesso ao serviço. Nesse contexto a própria estrutura da consulta médica individual se tornava fator de adoecimento profissional por não comportar em seu formato a gama de informações e sentimentos produzidos quando se busca uma abordagem mais integral do ser humano.

A necessidade de construir mapas que nos ajudem a situar e guiar nossa prática ressalta o trabalho em equipe interdisciplinar como essencial a esse fazer. ${ }^{7}$ Nesse aspecto, a figura do agente comunitário de saúde, profundo conhecedor do território comunitário, representa o elo entre realidade objetiva e saber técnico na APS. O mapeamento do território, as redes informais de cuidado, seu fortalecimento e inclusão na rede formal de atenção à saúde exigem esforço continuado e consciente do MFC em seu trabalho cotidiano junto às comunidades, movimento para o qual o agente comunitário de saúde (ACS) é um ator fundamental. 
Surgia, assim, a necessidade de uma abordagem coletiva dentro da minha prática médica visando a manutenção e aprofundamento de uma vinculação terapêutica entre indivíduos, comunidade e a equipe de saúde. Esse movimento de abertura para o coletivo coexistiria e dialogaria com a estrutura engessada e pré-estabelecida para o fazer médico na APS dentro da realidade objetiva vivenciada no cotidiano do MFC no município de Fortaleza, demandando novas tecnologias capazes de me permitir acessar a dimensão coletiva por trás de cada indivíduo atendido sem sucumbir às adversidades do cotidiano.

Segundo Freire: "Daí, a necessidade que se impõe de superar a situação opressora. Isto implica no reconhecimento crítico, na "razão" desta situação, para que, através de uma ação transformadora que incida sobre ela, se instaure uma outra, que possibilite aquela busca do ser mais."

Nessa perspectiva, de acordo com as recomendações de Rivieri, buscou-se operar o esquema conceitual, referencial e operativo (ECRO) da promoção em saúde comunitária a partir de uma experiência grupal. ${ }^{8} \mathrm{O}$ grupo de promoção à saúde na APS, segundo essa ótica, constituiria-se a partir da convergência dos saberes populares individuais e coletivo com o saber biomédico, através da utilização de ferramentas para a coordenação e integração do trabalho com grupos espaço para a gestação de um novo saber includente e efetivo.

\section{Duas realidades e a escolha do caminho a ser percorrido}

A organização do grupo para promoção em saúde surgiu em resposta a questionamentos relativos às limitações da prática médico-higienista na obtenção de resultados mais concretos e duradouros na manutenção, promoção e restabelecimento da saúde individual e comunitária e da minha própria realização profissional de conseguir dominar minimamente as competências exigidas ao MFC no dia a dia do exercício profissional.

Trago aqui minha primeira experiência com o planejamento, execução e manutenção de um grupo em saúde, tendo em vista que até então não existiam condições objetivas estruturais, de tempo, logísticas e de respaldo junto à gestão da saúde municipal para o estabelecimento de grupos para promoção em saúde de uma maneira mais sistemática e sustentável. Naquela realidade inicial qualquer iniciativa da minha parte recairia no modelo biomédico e implicaria em maior sobrecarga sobre mim.

Essas novas condições precisaram ser construídas a partir de avanços e retrocessos no processo de vinculação entre ESF e comunidade. Esse movimento de superação também não poderia advir das outras categorias de profissionais assistenciais da saúde, as quais, a meu ver, têm importância fundamental, no entanto, o que trago para discussão diz respeito às práticas médicas no contexto da APS e da ESF.

São estas práticas que refletem minha busca em construir, no contexto da APS, a práxis na qual eu, enquanto médico, possa enxergar e abordar essas contradições e assim, quem sabe, contribuir para o movimento de efetivação de um perfil adequado para atuar de acordo com uma matriz de habilidades necessárias ao desempenho pleno da Medicina de Família e Comunidade.

Minha aproximação com essas novas linguagens e ferramentas para a abordagem coletiva se iniciou com a participação em uma formação em terapia comunitária no contexto do movimento de saúde mental e comunitária do Bom Jardim (MSMCBJ) ainda no meu primeiro ano como residente em MFC. 
Um desafio que se revelou nesse percurso e que me motivou a construir esse relato foi o de tornar a minha prática médica menos impessoal, sem perder a qualidade dos resultados no que se refere a uma abordagem clínica efetiva e com responsabilidade sanitária pelos indicadores. Desse modo, busquei âncora nas teorias e conceitos humanísticos para problematizar as barreiras, resistências e dificuldades que surgem sempre que se tenta enfrentar a correnteza do modelo hegemônico biomédico e debater à luz dessas teorias, ainda contra-hegemônicas no campo da saúde, formas alternativas de cuidado.

A primeira dificuldade enfrentada na implantação dessa experiência foi a de sair da minha zona de conforto dentro da lógica biomédica em que fui treinado e partir para águas mais profundas e não navegadas do cuidado. Aqui eu sairia do papel de detentor do conhecimento e de prescritor de regras a serem seguidas sob pena de adoecimento e morte para uma atuação como uma espécie de animador ou motivador que funcionaria dentro de um grupo na busca de enxergar a saúde através de novos prismas.

A segunda barreira encontrada foi proteger um horário na agenda de atendimentos para realizar o atendimento coletivo. A partir de uma pactuação com a coordenação da unidade, onde houve uma expansão do território adstrito, englobando uma microárea, há muito tempo sem ACS responsável, foi possível estabelecer duas horas semanais para realização dos grupos.

Esta experiência incipiente a meu ver se mostrou um potencial para diminuir minha sobrecarga emocional enquanto provedor e responsável pela manutenção, restabelecimento e promoção da saúde de uma população adstrita na medida em que envolvia novos atores dentro da própria unidade e fora dela.

A mobilização de recursos terapêuticos e de cuidado presentes no território que vinham funcionando de maneira isolada e fragmentada, reproduzindo o modelo hegemônico de cuidado biomédico, buscava fortalecer uma visão mais global e integral da saúde. Essa seria a tônica desse processo que se iniciava, o qual, apesar de pouco visível em nível de macrossistemas, é bem difundido nos microssistemas de saúde no nível comunitário.

Finalmente o primeiro encontro. Naquele momento cada participante pôde se apresentar e começar uma construção da identidade de grupo. A partir de uma intervenção expositiva dialogada, busquei problematizar o conceito ampliado de saúde, promoção de saúde e fatores determinantes de saúde individuais e coletivos. Mais do que respostas, eu trouxe questionamentos e através da oportunização das falas e de uma escuta ativa foi possível estimular a participação de todos. Esse momento possibilitou a ampliação da visão de todos (inclusive a minha própria) trazendo para o centro a pessoa e não a doença. Deixar que os próprios participantes exemplificassem e se apercebessem desse universo específico da realidade de cada um, na maioria das vezes inacessível ao profissional biomédico assistencialista, foi fundamental e isso pôde ser registrado por meio de um questionário sobre autopercepção do processo saúde doença e dos recursos terapêuticos utilizados como forma de complementar o que foi expresso nas falas.

Naquele momento pude refletir como o sistema biomédico nos induz a ver o paciente de maneira fragmentada e como este também passa a ver o médico de forma desumanizada, como mero ditador de regras e normas a serem seguidas hierarquicamente para resolução de problemas relacionados à saúde e que fugiram do controle individual, provocando algum grau de sofrimento e forçando-o à procura de ajuda externa. A esse fenômeno chamei de "efeito da casa de espelhos". A vivência no grupo pareceu-me deixar patente que a confiança, respeito e valorização das pessoas pelo saber médico deve ser levada em conta quando se propõe uma mudança nessa relação. 
Outro aspecto observado foi a existência de uma confusão de conceitos entre promoção em saúde com prevenção de agravos, a qual precisava ser clarificada, mas não de uma forma meramente cognitiva e sim experiencial e sensorial para ser significativa. Assim, pactuamos que trabalharíamos no grupo ressaltando os fatores positivos promotores de saúde existentes em cada indivíduo.

Nessa altura dos acontecimentos o primeiro encontro do grupo já havia acontecido e tinha tratado, como dito anteriormente, do conceito de promoção de saúde, que seria o fio guia para os encontros subsequentes. E eu já buscava novas vivências que permitissem a formação do conceito de promoção em saúde em nível individual e coletivo a partir da construção de uma identidade grupal.

Nas semanas seguintes ao voltei meu olhar para o território em busca de parcerias na construção desse novo modelo de cuidado. Fazia-se necessário percorrer o território e encontrar os outros atores em contínuo movimento no seu interior. No entanto, o cotidiano dos serviços de saúde me prendia ao atendimento de problemas individuais, dificultando enxergar o entorno e suas potencialidades.

Percorrendo o território utilizando meu horário reservado para a educação permanente fui reconhecendo alguns de seus recursos e equipamentos de saúde. O recurso do matriciamento em saúde mental foi a primeira ferramenta que lancei mão com o objetivo de construir novas linguagens para a comunicação coletiva, fazendo uma parceria com o Centro de Atenção Psicossocial (CAPS) geral da regional IV. Por meio do conhecimento da assistente social daquele serviço sobre o território, começamos a percorrer de forma sistemática os equipamentos de saúde no território e construir pontes para a otimização do cuidado.

Assim, chegamos ao CAPS álcool e drogas (AD), onde prontamente foi estabelecida a possibilidade de capacitar os ACS da equipe em uma oficina de arte terapia e manufatura através de um minicurso dividido em quatro encontros a ser ministrado pela arte terapeuta Magda naquele equipamento do território. A incorporação dessa nova tecnologia educativa e terapêutica pelos ACS foi imediatamente atrelada à realização do segundo encontro do grupo de promoção em saúde. Aqui o apoio da coordenação da unidade, liberando os ACS para estarem presentes na capacitação um turno por semana durante um mês, foi fundamental para a viabilização da continuidade da proposta inicial do grupo de promoção em saúde.

O segundo encontro do grupo consistiu então na execução da oficina de manufatura da qual os ACS foram os monitores, coordenadores e mediadores nesta etapa e colocaram em prática seus conhecimentos adquiridos na capacitação promovida pelo CAPS AD. A mim coube o papel de observador ativo durante o processo.

O trabalho com a manufatura enriqueceu o fazer profissional do ACS e lhes ampliou os recursos para abordar no território determinantes de saúde como a socialização de idosos, a ressignificação de perdas e de adoecimentos e controle de fatores associados à ansiedade e depressão na terceira idade. A abordagem de conceitos como a terapia ocupacional comunitária e a economia solidária promoveu a cooperação, a amorosidade e a solidariedade dentro do território.

Nesse encontro contamos também com o auxílio de uma artesã da comunidade, a qual a partir desse momento assumiu um papel ativo no processo da intervenção, contribuindo para a consolidação da atividade e da experiência grupal. Surgia do seio da comunidade nova referência de instrumento de produção de saúde. 
Ao final, houve um rico momento de troca e sistematização das experiências individuais durante a prática. Esse momento fortaleceu ainda mais os vínculos através da identificação com o trabalho do outro e o empoderamento do grupo sobre a possibilidade de transformações e intervenções na realidade objetiva e sua identidade grupal.

Vivenciei, dessa forma, um fortalecimento do vínculo entre equipe e pacientes, no qual foram valorizados o saber popular e um aumento na compreensão do agente comunitário de saúde sobre seu papel e importância no funcionamento pleno da ESF e dos recursos terapêuticos comunitários.

Seguindo a mesma linha de organização e planejamento, os ACS participaram de nova capacitação com a psicóloga do CAPS geral em técnicas de atividades corporais e sensoriais. Assim, trouxeram para o terceiro encontro do grupo a técnica do desenho às cegas e intuitivo, na qual partir de rabiscos com os olhos fechados as pessoas intuíam observando o desenho feito às cegas padrões que pudessem ser transformados em um desenho inteligível e com significado a ser então explanado para o resto do grupo.

Esse momento constituiu-se em grande desafio aos participantes. Ficou patente a dificuldade de lidar com a privação de um único sentido (a visão) durante a elaboração inicial e a seguir de abstrair novos significados a partir do desenho inicial. Para aquelas pessoas, a realidade objetiva constitui-se dura e quase imutável, o que exigiu um esforço imenso dos observadores e dos próprios participantes para ressignificar cada desenho produzido ao final da atividade devido à concretude do produto individualmente elaborado. O feedback da consolidação do trabalho desenvolvido e do significado individual se apresentava como um registro físico - o desenho e oral - a explicação do significado para o grupo.

Esse movimento gerava uma comunicação efetiva intragrupo na qual a exposição através da fala do significado da representação pictórica gerava sentimentos nos demais integrantes e ouvintes que se manifestavam trazendo novos significados a partir de suas visualizações individuais baseadas na história de vida específica de cada pessoa. Aqui tivemos um salto na consolidação de uma identidade grupal e um estreitamento dos laços entre aquelas pessoas, pacientes e equipe. Novamente fortaleceu-se o papel do ACS na busca e na utilização de linguagens diversas para além do discurso biomédico capazes de impactar tanto quanto ou mais na saúde e no bem-estar das pessoas.

O quarto encontro foi pensado então como o encaminhamento para o fechamento daquela experiência. Nessa perspectiva, o grupo buscaria ir integrando e ressignificando o aprendizado a partir dos conceitos trabalhados anteriormente, enquanto eu fui buscar na minha formação como terapeuta comunitário a ferramenta que poderia se adequar aquele momento do processo. Dentro do território contamos com esse recurso, que é desenvolvido semanalmente por um terapeuta comunitário em equipamento municipal de recursos humanos. Assim, a Terapia Comunitária Integrativa $(\mathrm{TCl})$ como ferramenta da ASC foi utilizada para guiar o grupo rumo à sistematização daquelas vivências. Fruto dessa interação foi elaborado um instrumento de referência entre APS e TCI.

Do princípio básico tiramos a lição coletiva de que precisamos fazer um esforço para verbalizar, transmitir e significar para o outro nosso sofrimento, dor ou incômodo para que no simples ato de externar o que estamos sentindo mobiliza processos internos de autocura e de restabelecimento do bem-estar e do equilíbrio interior. 
No fechamento da roda de $\mathrm{TCl}$ um tema ou problema trazido até o grupo foi elegido entre os participantes e foi aprofundado através de perguntas diretas sobre o assunto ao membro que trouxe a temática elegida*. Essa foi uma oportunidade de revisitar sentimentos, impressões e recursos individuais no enfrentamento e solução das dificuldades apresentadas. A palavra escolhida naquela oportunidade foi a discriminação sofrida e relatada por uma participante da roda. Esse mote ressoou forte dentro do grupo, considerando que este era formado por pessoas advindas de situações limites que praticamente todos já haviam enfrentado. A empatia e a solidariedade foram instantâneas.

Apesar de ter sido realizada de uma forma experimental, ficou explícito o poder da ferramenta $\mathrm{TCl}$ para aumentar o conhecimento entre as pessoas, suas histórias de vida e seus aprendizados dentro dessa caminhada e para o fortalecimento de uma identidade grupal. E na minha avaliação apontou claramente para um resultado positivo em direção aos objetivos estabelecidos.

No quinto encontro aportamos ao final do processo, que consistiu em um agradecimento da equipe pela participação dos convidados e na gratidão de todos por haverem partilhado aqueles encontros. Nas falas dos participantes não pude deixar de perceber uma leve frustração da ideia inicial que os usuários traziam do grupo como uma oportunidade de ter um acesso mais facilitado ao atendimento médico, mas que no geral estavam satisfeitos por terem tido a oportunidade de falarem mais abertamente e exporem suas opiniões perante um grupo formado por seus pares, bem como pela ESF, que pôde atuar de forma interdisciplinar e colaborativa.

Esse aspecto também demonstrou que o objetivo de fazer um grupo e não um atendimento individual em grupo fora até certo ponto atingido. Nesse momento também surgiram sugestões de temas de interesse a serem abordados em novos encontros, mostrando a valorização e a importância da manutenção de espaços para a atividade em grupo dentro da rotina da APS.

A existência de uma barreira com relação à comunicação escrita dificultou a expressão de opiniões por esse canal. Por isso, a importância de gerar e valorizar a produção material, manufaturas, desenhos e registros orais a fim de termos uma comunicação efetiva.

Nesta síntese final pude perceber a permanência de certos conceitos e visões hierárquicas do processo saúde-doença enquanto um conhecimento específico biomédico e que requer a intervenção médica ou da enfermagem para seu manejo por meio de uma ação meramente prescritiva e vertical da relação médico-paciente e do papel passivo do indivíduo nessa relação.

No entanto, também pude identificar indícios de um germe de mudança no qual saímos da linearidade do processo saúde-doença (prescrição, obediência e cura) para uma estrutura mais circular desse processo, na qual o paciente consegue refletir e trazer novos elementos que lhe façam sentido dentro de seus sistemas de cultura, crenças e tradições para contribuir no restabelecimento, manutenção e promoção da saúde. Essa modificação ou ampliação de horizontes se manifestava na associação de orações, meditação, do silêncio, do aquietar, do descanso e do recolhimento como importantes recursos na manutenção da saúde que não fazem parte do discurso biomédico tradicional.

Durante todo o processo, pude observar a ocorrência de um fenômeno interessante que muito me impressionou no qual algumas pessoas que chegaram como objetos de uma intervenção passaram a 
sujeitos da mesma colaborando ativamente de maneira mais proativa, apoiando o grupo, sugerindo novos materiais que pudessem estar sendo trabalhados em grupos específicos e que seus produtos poderiam compor uma exposição ou bazar solidário estimulando a economia comunitária, gerando autoestima e reconhecimento ao grupo. Ou no sentido inverso quando os membros da ESF se sentiam fortalecidos em sua prática profissional e enquanto seres humanos.

Ao final do processo vivido, a implantação do horto comunitário da UAPS Luís Costa, através da articulação e parceria entre UAPS, Farmácia Viva Municipal Lúcia Rangel, Conselho Local de Saúde e comunidade, constituiu-se na materialização do arcabouço conceitual abordado durante os encontros narrados.

A manutenção de um horário protegido na agenda padrão semanal do MFC para o planejamento e realização de atividades coletivas pela ESF e comunidade constituiu-se em outra conquista rumo à concretização de uma nova abordagem da saúde comunitária.

\section{A realidade em um relance}

Na APS temos um espaço privilegiado e protegido para o encontro de saberes diversos. E um vislumbre do poder transformador quando se alia o conhecimento formal e acadêmico ao informal, vivencial e comunitário. Faz-se necessária a multiplicação desses espaços e das discussões dessas experiências em nível de atenção primária, seu reconhecimento e legitimação por parte dos poderes constituídos.

Semelhante a um telescópio de raios-x que após lançar a radiação no espaço deve manter seus sensores funcionantes para que somente depois de decorrido um bom tempo pudesse coletar processar e analisar as informações obtidas a partir do movimento inicial, o trabalho para a promoção de saúde comunitária deve permanecer sensível aos seus efeitos sobre a saúde das pessoas e das coletividades envolvidas por um período de tempo ainda indeterminado.

Aqui lançamos mão da problematização para com base no processo do agir, refletir e agir novamente, entrar na espiralidade da construção do conhecimento, buscando avançar em processos educativos que efetivem a promoção à saúde comunitária. Nesse contexto, descortinam-se infinitas possibilidades de ação do MFC enquanto membro fundamental da ESF para além do aspecto assistencialista.

A valorização e priorização de estratégias para a promoção de saúde e para uma mudança do olhar sobre as prioridades em saúde da população assistida a partir de uma construção conjunta e os benefícios advindos dessas práticas impactam não somente sobre a população, mas sobre o profissional e toda a eSF.

Percorrendo o caminho que vai do adoecimento ao prazer de viver uma vida plena e autônoma, o MFC se propõe, ao abraçar a especialidade, elevar a saúde ao seu mais alto patamar nos diversos aspectos que a constituem.

Sem abandonar os princípios clínicos que regem o meu fazer médico e me rendem a admiração e respeito da população a qual assisto, pude enfim firmar o passo rumo à minha plena realização profissional, agora não mais como um residente aspirante, mas como Especialista em Medicina de Família e Comunidade. 


\section{Contribuição dos autores}

Concepção e/ou delineamento do estudo: ACM. Aquisição, análise ou interpretação dos dados: ACM. Redação preliminar: ACM. Revisão crítica da versão preliminar: ACM. $O$ autou aprovou a versão final e concordou com prestar contas sobre todos os aspectos do trabalho.

\section{Conflito de interesses}

Declara não haver.

\section{Referências}

1. Jara-Holliday O. A sistematização de experiências, prática e teoria: para outros mundos possíveis. Tradução Gafrée L, Pinevro S; colaboração Falkenbach EMF. Brasília: CONTAG; 2012.

2. Barbier R. Pesquisa-ação. Brasília: Liber Livro; 2002.

3. Freire P. Pedagogia do oprimido. $17^{a}$ ed. Rio de Janeiro: Paz e Terra, 1987.

4. Dantas VLA. Dialogismos e arte na gestão em saúde: a perspectiva popular na experiência das Cirandas da Vida em Fortaleza-CE [tese]. Fortaleza: Universidade Federal do Ceará; 2009. 323 p.

5. World Health Organization (WHO). Primary health care: now more than ever. Geneva:WHO;2008 [Acesso 9 de maio de 2017]. Disponível em: http://www.who.int/whr/2008/whr08_en.pdf

6. Merhy EE. A saúde pública como política. São Paulo, 1920-1948, os movimentos sanitários, os modelos técnico-assistenciais e a formação das políticas governamentais. São Paulo: Hucitec; 1992.

7. Merhy EE. Saúde: A Cartografia do trabalho vivo. 3ae ed. São Paulo: Hucitec; 2002.

8. Pinchon-Rivière E. O processo grupal. São Paulo: Martins Fontes; 1988. 